\title{
A ADOLESCÊNCIA SOB A LENTE DA PSICANÁLISE ARTICULADA AO SOCIAL
}

Vinicius Romagnolli Rodrigues Gomes*

RESUMO: Este artigo tem como proposta compreender a adolescência sob a ótica psicanalítica articulada ao social, considerando a adolescência uma configuração específica da estrutura histórica, na qual o sujeito se constrói na/pela relação com o outro, pela via social, cultural. Argumentamos que a Psicanálise, como método de análise, baseia-se na visão histórica da subjetividade, que identifica as transformações do ethos cultural e suas implicações para o sujeito; pensando o psíquico em sua articulação com os acontecimentos histórico-sociais. Tal análise pode contribuir para ampliar a compreensão acerca dos adolescentes.

PALAVRAS-CHAVE: Adolescência; História; Psicanálise.

\section{ADOLESCENCE FROM THE POINT OF VIEW OF SOCIAL-LINKED PSYCHOANALYSIS}

ABSTRACT: Adolescence is investigated from the point of view of social-minded psychoanalysis. Adolescence is a specific configuration of a historical structure where subjects construct themselves within and through their relationships with others, socially and culturally. As a method of analysis, Psychoanalysis is based on the historical stance of subjectivity which identifies the transformation of cultural ethos and its implications on the subject. The psychic stance is thought in its articulation with historical and social events. Current analysis may contribute towards an indepth study on adolescence.

KEY WORDS: Adolescence; History; Psychoanalysis.

\section{INTRODUÇÃO}

Este artigo é fruto de uma dissertação de mestrado, na qual estudamos a

\footnotetext{
"Mestre em Psicologia pela Universidade Estadual de Maringá UEM). Docente no curso de Psicologia do Centro Universitário de Maringá (UNICESUMAR), Brasil. E-mail: viniciusromagnolli3@hotmail.com
} 
adolescência na contemporaneidade em meio a sociedade de consumo (GOMES, 2014). Neste estudo constatamos diferentes olhares acerca do processo adolescente, sendo que a definição de adolescência é marcada por discordâncias entre uma perspectiva desenvolvimentista que a concebe como etapa do desenvolvimento humano; e a perspectiva histórica e social que questiona a ideia de adolescência como um processo natural do desenvolvimento e critica o uso do conceito como universal.

A leitura desenvolvimentista entende a adolescência como uma etapa que possui características específicas, tais como a insegurança, a rebeldia, a impulsividade e a agressividade. Tais características seriam consequência das mudanças biológicas e hormonais que se processam nessa fase, e que fixam o adolescente em um período de transição entre a infância e a fase adulta. De acordo com esta perspectiva, a adolescência é um fenômeno universal e generalizado, baseando-se na razão como principal mecanismo de apreensão e de vivência no mundo, pois seria a partir do amadurecimento e do predomínio da razão que o sujeito atingiria a maturidade. Esta visão cartesiana racionalista traz em seu bojo a crença em uma identidade adolescente que definiria a personalidade do sujeito para o resto de sua vida (COIMBRA, 2005).

Esta perspectiva naturalista e evolutiva é produto do positivismo e opera uma fragmentação do processo histórico em etapas, a serem estudadas isoladamente e descritas estaticamente, excluindo movimento e contradições. A concepção positivista busca as uniformidades empíricas aparentes, as quais não dizem nada sobre a realidade subjacente que elas expressam. Tais teorias evolutivas, ao falarem da adolescência como "cataclismo", supõem a oposição de duas realidades diferentes e com certo grau de independência entre si; nesta concepção do desenvolvimento, torna-se difícil incluir o processo adolescente, que chega a ser visto, em certos casos, como um fenômeno psicopatológico.

Uma das principais críticas feitas à perspectiva desenvolvimentista é pautada na ideia de evolução até a maturidade, pois, a partir dela, o adulto seria entendido como ideal de completude a ser alcançado (CALLIGARIS, 2000; COIMBRA et al. 2005).

A crítica também é dirigida ao entendimento do adolescente como ser incompleto, que necessita de uma identidade estável, fixa e madura para ser 
reconhecido na rede social. Nesse sentido, vemos a necessidade de ir além de uma visão "naturalista", na qual a leitura psíquica fica atrelada ao campo do biológico, bem como de relativizar e contextualizar o registro biológico, inscrevendo-o e relacionando-o às séries institucionais e sociológicas (BIRMAN, 2006).

Bertol e Souza (2010) alertam que a descrição da adolescência como momento de constituição de uma identidade plena, coesa, adulta e que compreende a conclusão da constituição subjetiva esbarra na concepção da singularidade do sujeito e na irredutibilidade e mobilidade das pulsões, que são vistas como fundamentais para a subjetivação segundo a Psicanálise.

Nessa perspectiva, se reforçamos a ideia de manifestações naturais na adolescência, dificultamos a possibilidade de o sujeito se expressar em sua singularidade, ou ainda corremos o risco de não escutar a sua manifestação, encaixando-a nos padrões de anormalidade e normalidade consolidados pelos discursos desenvolvimentistas e reforçados pelos ideais modernos.

Para a teoria psicanalítica, a infância nunca desaparece, bem como nunca se alcança a maturidade sexual absoluta; não há, portanto, a substituição de uma velha estrutura por outra nova, mas sim uma transformação em algo novo que conserva algo do antigo em si. A organização sexual adulta contém as organizações sexuais infantis, sendo que estes elementos persistem ainda que ressignificados ou revalorizados.

Freud contribuiu para destruir o "mito da idade adulta", o que nos leva a questionar os valores normativos de estabilidade e maturidade (TUBERT, 1999). Cada experiência vivida influi no desenvolvimento posterior, os elementos de fases anteriores são retidos e ao mesmo tempo o novo não desloca o antigo, mas o transforma. Assim sendo, seria ilusório falar em "fases" sucessivas, pois alguns fenômenos iniciais só adquirem sentido em momentos posteriores como nos mostra Freud (1905/1996).

Freud (op.cit) associou a sexualidade com as manifestações pulsionais, que antes de serem determinadas pelo amadurecimento de aspectos biológicos, são constituídas e transformadas na relação com o outro, fator determinante na formação de objetos sexuais e de configurações subjetivas. Assim sendo, a ideia desenvolvimentista de que a vivência da puberdade estaria ligada a uma maturação 
biológica, bem como o estabelecimento de uma cronologia para sua ocorrência, se chocam com a noção de sexualidade e de sujeito singular propostas por Freud, pois mantêm uma relação de causalidade linear e direta entre as mudanças orgânicas e os processos subjetivos destinados à adolescência.

Para Freud, são as relações estabelecidas pelo sujeito que deflagram os caminhos da sexualidade e os processos subjetivos que delas decorrem. Freud (1921/2010), já apontava isso ao falar da impossibilidade de separar o social e o individual. Nesse sentido, vemos que a puberdade está sujeita à rede social que está, por sua vez, atrelada ao contexto cultural no qual o sujeito está inserido, bem como à história singular deste, envolvendo suas fantasias e desejos (BERTOL; SOUZA, 2010).

Como para a psicanálise a constituição psíquica advém das marcas identificatórias, podemos considerar que o indivíduo é o resultado de sua história e não pode ser destacado do campo social no qual está inscrito. Nesse sentido, Matheus (2002) aponta a adolescência como um fenômeno duplamente histórico:

Enquanto o modo como o fenômeno da juventude se configurou na modernidade, resultante da falência de dispositivos, tais como ritos articuladores da passagem do universo infantil ao adulto, e, também, como expressão de determinadas questões sociais reformuladas por estes sujeitos em seu questionamento (p. 94).

Birman (2006) enaltece que a Psicanálise de Freud teve o mérito de desbiologizar a sexualidade e de inscrevê-la num registro simbólico, contribuindo para desnaturalizar sistematicamente a concepção de infância na tradição ocidental e lembrar sua dimensão histórica. Já Tubert (1999) formula uma crítica às teorias que consideram a infância e a adolescência como meras etapas, caracterizadas pela imaturidade e com caráter provisório a caminho de uma maturidade definitiva.

Para a autora, a maturidade seria uma "máscara" que reforça a fronteira entre infância e idade adulta, ocultando aspectos que poderiam ser considerados como sinais inaceitáveis de maturidade (indecisões, dúvidas, por exemplo). Por trás de tal máscara, o adulto se veria obrigado a rejeitar sua infância e adolescência como fases preparatórias que supostamente ficaram para trás.

Nesse sentido, conceitos como: maturidade, estabilidade, equilíbrio e idade 
adulta entraram em crise, já que fazem parte de ideologias repressivas, a serviço da manutenção da ordem estabelecida. De acordo com os ideais e valores dominantes na sociedade em dado momento histórico, certos "resultados" produzidos com maior frequência pela estrutura são tomados como "ideais" e transformados em "finalidades".

Diante disso, Tubert (1999) propõe uma concepção da adolescência como uma configuração que não começa ou acaba em um dado momento da vida, mas sim como produto de uma história que se inicia com o nascimento da criança e até antes disso, quando aparece o projeto de vida na história daqueles que a geraram. Os fenômenos que aparecem como naturais no adolescente são, na verdade, produtos de vínculos humanos cristalizados; há, portanto, uma relação dialética entre a história, que é reconstrução e não evolução das relações intersubjetivas, e a situação presente, que atualiza e revela o histórico, ao mesmo tempo em que lhe confere uma nova significação.

A Psicanálise entende que a subjetividade é constituída através de identificações, as quais são operações dinâmicas e imprevisíveis que outorgam ao sujeito uma plasticidade. Freud (1921/2010) considera a identificação como uma ligação libidinal de amor primitiva e inibida quanto aos desejos sexuais, que seria capaz de superar os narcisismos individuais e o ódio que separa uns dos outros; sendo a força responsável pela união dos indivíduos entre si. Além disso, a identificação possibilita a elaboração da constituição subjetiva, operando a partir de modelos parentais e sociais que servem de referência, sendo, portanto, um processo singular que pode ocorrer em várias direções.

Ao pensarmos a adolescência, esse conceito fica ainda mais claro, tendo em vista que sua identidade será resultado do reconhecimento e elaboração de diversas identificações parciais, que vão se incorporando no sujeito, desde os primórdios, pela introjeção de valores parentais e sociais. Devemos ressaltar que a aquisição de novas identidades na adolescência não suprime as anteriores, sendo que emergem no $e u$ tanto aspectos primitivos quanto atuais da personalidade, o que equivale a dizer que o processo de identificação prossegue por toda a vida e não para na vida adulta.

Os processos identificatórios ocorrem por meio da síntese egóica, devido 
a novas distribuições da libido e pela transformação de valores e ideais. Isso se processa a partir de movimentos psíquicos existentes na relação entre pais e filhos, sendo que estes incorporam, desenvolvem e transformam seu modo de ser, pensar e viver buscando seus próprios modelos. A cultura se faz presente neste processo, quer seja pelo modelo identificatório dos pais ou pela ação direta sobre os adolescentes (LEVISKY, 1998).

Falar em adolescência e processos identificatórios implica necessariamente em falar das formações grupais, que se tornam uma das fontes de gratificação e de suporte narcísico para o adolescente. A relação estabelecida entre o adolescente e o grupo tem o papel de substituto do ideal de eu, ou seja, atua como mediadora de sistemas de identificação e de identidade. Marcelli (2009) aponta que o ideal de eu na adolescência se serve do grupo como substituição de identificação e de gratificação narcísica.

Assim sendo, podemos considerar que o surgimento dos amigos e dos grupos como novos objetos de investimento amoroso e sexual representa algo narcísico, próximo de um objeto idealizado de si mesmo e projetado no(s) companheiro(s) (LEVISKY, 1998). O adolescente, com sua tendência a rejeitar os objetos parentais e multiplicar suas experiências, tem, nas novas relações de objeto, um suporte para as interiorizações e identificações futuras.

Há, portanto, uma busca por realizar apropriações identificatórias, as quais dependem em grande medida, de "objetos mediadores" que são encontrados em especial em outros adolescentes e no(s) grupo(s) (EIZIRIK, 2009).

Kehl (2004) destaca que a saída da infância suscita formações fraternas que servem de ancoragem para novas identificações, por isso, a adolescência é um período no qual a formação de grupos tem grande importância para o desenlace da relação edipiana com os pais.

Além disso, pertencer a um grupo é uma espécie de "novo batismo" para o adolescente, bem como um auxílio na transição das identificações infantis para um novo campo identificatório em meio à tentativa de superar as referências familiares de até então. O grupo pode funcionar ainda para o adolescente como uma espécie de autorização e incentivo das experiências transgressivas, essenciais para a simbolização da lei e a relação com as restrições impostas por esta.

A despeito dessa críticas, vemos que o discurso desenvolvimentista 
segue sendo reforçado pelas práticas e discursos sociais e científicos apagando a construção social que sustenta o conceito de adolescência, fortalecendo-o como modelo e parâmetro de normatização e de classificação dos sujeitos de nossa cultura. A partir desta perspectiva, os adolescentes são representados por excelência como "rebeldes" que vivem em constante conflito.

Lembremos que o conceito de adolescência surgiu diante do cenário de individualismo e ideal de liberdade, o que permitiu a caracterização da adolescência como um período de conflito e de oposição às normas sociais. Assim, compreender a atribuição dessas qualidades e a contextualização desse conceito é fundamental para o entendimento desse tema frente ao discurso social que se apresenta atualmente sobre o adolescente (BERTOL; SOUZA, 2010).

A leitura desenvolvimentista, ao enquadrar a adolescência em determinados padrões, acaba-se desresponsabilizando os sujeitos nessa fase da vida, por entender que estão em um período de transição no qual a transgressão é naturalizada. No entanto, ao mesmo tempo em que são desresponsabilizados, exige-se uma punição para seus atos, explicitada na demanda social pelo estabelecimento de leis sociais cada vez mais rigorosas, como é o caso da discussão em torno da redução da maioridade penal.

Bertol e Souza (2010) consideram que a imposição de práticas, significados e modalidades de pensar e de sentir estabelecidas como naturais e normais ocultam o jogo de forças presente na rede social e exercem uma violência contra os adolescentes. Ao adotarmos, nesse artigo, a Psicanálise em sua perspectiva histórica e social, visamos não reproduzir tal violência.

Partindo desse pressuposto, iremos analisar doravante a "construção da adolescência" a partir da Modernidade, tendo em vista que esse resgate historiográfico nos possibilita pensar a adolescência tal como ela se configura na contemporaneidade, ou seja, como uma experiência individualizada, na qual cada um estabelece um caminho próprio diante dos impasses dessa transição que surgem em função do modo de organização social que se estruturou na modernidade.

Além disso, tal resgate nos permite discriminar as diversas versões da adolescência, bem como escrever a história na psicanálise, observando a tensão que surge entre o pensamento psicanalítico e a tradição da história. 


\section{DESENVOLVIMENTO}

A presença dos termos "adolescência" e "juventude" em diferentes momentos históricos, não traduz uma constância semântica destes vocábulos, pois os sentidos do termo variam e os conteúdos semânticos renovam-se (MATHEUS, 2010). A palavra "adolescência" é de origem latina e vem do verbo adolescere, que significa desenvolver-se, crescer; e que é próximo do termo addolescere, que significa adoecer. A proximidade dos dois sentidos anuncia a dimensão de "crise" que ficou associada à adolescência a partir da Modernidade.

No início da era moderna a juventude era vivida como fase de iniciação e transição para a vida adulta, pautada por ritos de passagem, sendo que os jovens promoviam a formação de grupos segundo a idade e ofereciam toda uma série de ocasiões de autoeducação e de representação de si no interior do grupo. Isso nos mostra como a ocupação dos espaços simbólicos por parte dos jovens estava presente na cultura daquele tempo.

Essas manifestações eram toleradas pela cultura da época que, apesar de realizar certo controle, respeitava a necessidade social desses ritos. Deste modo se espalhava a consciência de que a troca de gerações era quase uma necessidade estabelecida pela lei da natureza, mas também uma atitude de confiança na sociedade, orientada para o futuro (GURSKI, 2012).

A noção de adolescência e juventude passou a adquirir um status mais discriminado com o nascimento do Estado Moderno e a ideia de nação no final do século $\mathrm{XV}$, sendo que os fundamentos de autodeterminação e a racionalidade do Estado moderno incitaram a busca por ação, previsão e controle sobre o sujeito social que culminou com a periodização das etapas da vida marcada pelo fortalecimento da concepção de que a formação do indivíduo depende de etapas sucessivas que passam a ser vividas nos hábitos e costumes da sociedade europeia.

Diante disso acompanhamos uma distinção de um universo infantil com características próprias, a ser preservado e regrado, também vai se tornando mais clara a etapa situada entre esse primeiro período e o mundo adulto (MATHEUS, 2010).

E foi nesse contexto do Estado Moderno que surgiu o ensino secundário como resultado do projeto Iluminista que promoveu o acesso ao colégio e ao 
liceu. Esse processo irá se consolidar no século XIX com a escolarização, a primeira comunhão e o serviço militar, práticas que fortalecem a escola e o exército enquanto instituições.

Entretanto, como destaca Matheus (2010), tal acesso era restrito aos privilegiados que não tinham que trabalhar. Ainda assim, o papel das instituições educativas foi decisivo na constituição do homem moderno, reinventando as idades da vida de acordo com a educação e o grau de instrução que permitiam fabricar o "homem esclarecido". Vemos, portanto, que a escolaridade foi um dos critérios utilizados pela sociedade para demarcar a progressão do jovem ao estado adulto (LEVISKY, 1998).

A partir do século XVIII, com o crescimento das cidades, as transgressões, antes vistas como reivindicação coletiva, passam a ser encaradas como ação individual e fonte de ameaça para a cultura "civilizada" que se impunha (MATHEUS, 2010). Nesse sentido iniciou-se um movimento legal, cuja finalidade era acabar com a tolerância aos atos insolentes dos jovens. Os ideais iluministas, com sua ode à ordem e ao Estado, passaram a subtrair a importância da juventude arruaceira (GURSKI, 2012).

O conceito de adolescência ganhou hegemonia ao longo da modernidade, sendo que as características psicológicas e biológicas desta etapa foram sendo determinadas, tornando-a um objeto naturalizado. Foucault (1988) mostra que foi a perspectiva assentada na continuidade e linearidade do desenvolvimento, do progresso e do tempo histórico que possibilitou essa naturalização da concepção do humano calcado em etapas.

Os estudos psicológicos e biológicos atrelados aos pressupostos modernos foram os responsáveis pela atribuição de características tidas como inerentes à fase da adolescência, permitindo a classificação dos sujeitos em relação às fases estabelecidas (COIMBRA, 2005).

Em meio a esse processo de construção de saberes sobre as fases do desenvolvimento humano, os estudos científicos produziram normatizações para reiterar e reproduzir essa conformação subjetiva conforme os atributos estipulados. As fases do desenvolvimento passaram a constituir foco de interesse das áreas do saber modernas, como a Psicologia, a Medicina, a Pedagogia e o Direito, as quais 
passaram a legitimar a existência do adolescente de acordo com o conhecimento que produzem sobre eles.

Pode-se dizer, portanto, que o "objeto adolescente" nasce a partir do discurso e da prática científica moderna, que lhe atribuem uma identidade marcada por características específicas e que lhe conferem individualidade (BERTOL; SOUZA, 2010).

Se o conceito de adolescência teve sua origem e história atreladas à modernidade, pensar a adolescência implica fazer menção ao contexto sociocultural individualista, no qual é delegada a cada indivíduo a responsabilidade de administrar seu próprio destino. Todo ideário que sustentará a noção de indivíduo eclode a partir da Revolução Francesa em 1789, sendo que o individualismo teve sua base nos princípios de igualdade e liberdade, e foi o valor fundador das sociedades modernas ocidentais, levando os homens a serem considerados livres perante o Estado.

O sujeito autônomo seria, nesse sentido, aquele que cria suas próprias leis e que exerce sua liberdade constituindo-se através da própria vontade (BERTOL E SOUZA, 2010). Esses ideais de um indivíduo autônomo e livre possibilitaram a concepção da adolescência, pois a partir deles criou-se a ideia de um homem supostamente capaz de autodeterminar-se, sendo responsável por suas ações e escolhas, o que implica dizer que o destino do homem não mais dependeria da sociedade e do contexto no qual está inserido.

Nesse sentido, a adolescência surge como um momento de preparação para o reconhecimento na rede social e para partilhar essa rede através de uma identidade definida, que seria a marca de conclusão do processo de amadurecimento. Durante tal processo, o sujeito enfrentaria conflitos e desafios a fim de tornar-se um indivíduo autônomo e capaz de se autodeterminar independentemente da organização social. Com isso, os momentos de crise, conflito e rebeldia são encarados como algo necessário para se atingir a autonomia e para alcançar o status de adulto, ideal de completude do sujeito moderno (BERTOL; SOUZA, 2010).

Diante disso, podemos compreender a ideia de adolescência que se forma no século XIX como resultado do processo de constituição do indivíduo, pilar de sustentação do Estado moderno e a "crise da adolescência" como consequência direta de tal processo; uma condição para a formação deste indivíduo. Logo, é a partir 
da modernidade que a adolescência é considerada um momento de turbulência decisiva na constituição do indivíduo.

Matheus (2010) destaca que a noção de "crise da adolescência" denota tanto um momento crítico como também sugere o potencial enunciativo que gira em torno disso; algo é enunciado seja sobre o adolescente seja sobre a organização social à qual pertence. Isso nos ajuda a lançar luz sobre os motivos pelos quais a adolescência foi associada ao longo do século XX, ora como solução e futuro da humanidade ora como problema e ameaça.

Assim sendo, podemos destacar mudanças na representação do "ser jovem", tendo em vista que cada momento histórico elege um período da vida para simbolizar seus ideais de perfeição e, na contemporaneidade, os jovens saíram de uma obscuridade culposa e obediente à qual os discursos médicos e morais os relegavam para se transformar em uma faixa da população privilegiada pela indústria cultural (KEHL, 2004).

Calligaris (2000) aponta, por sua vez, que a adolescência, na primeira metade do século XX, era vista como uma "etapa cronológica" e que, na segunda metade do mesmo século, passou a ser vista como um "grupo social" e como paradigma de um ideal cultural. Para o autor, a adolescência seria um derivado contemporâneo da infância moderna, a qual era vista pelos adultos como uma época de felicidade, sonhos e promessas.

Ao encarregar tal infância de preparar o futuro e alcançar um sucesso que faltou aos adultos, houve um prolongamento desta fase que resultou na adolescência. Essa transição da vida infantil para a adolescência como lugar de identificação e promessa teve influência de fatores sociais, econômicos e culturais, citando como exemplo a hegemonia americana, no período do Pós-Guerra que impôs uma série de novos hábitos e costumes, dentre eles, o blue jeans, traje popular que foi introduzido maciçamente nas universidades americanas por jovens que queriam distanciar-se de seus pais e que invadiu os lares do mundo inteiro (HOBSBAWN, 2002).

Este cenário faz com que autores afirmem que a adolescência, como grande ideal da vida adulta, foi inventada e vingou nos Estados Unidos, sendo originalmente uma concepção americana, ou seja, a cultura americana apresentou com vanguardismo o que seria a tônica de nossos dias: a exaltação do jovem e seu modus vivendi (GURSKI, 2012). 
Deste modo, a compreensão da juventude se passa pelo entendimento das demandas sociais que, desde a $2^{\mathrm{a}}$ Guerra Mundial, criaram a figura do teen. O período do welfare state, marcado pelo novo ciclo de desenvolvimento industrial e pelo crescimento da comunicação de massa, proporcionou condições sociais marcantes na condição juvenil do Pós-Guerra, dentre as quais podemos citar: a valorização do prazer e do consumo como fontes de gratificação imediata, que passou a ser o signo da juventude transviada da década de 50.

Nesse período, construiu-se um ideário social sobre o jovem como transgressor, o que pode ser visto pela produção literária da década de 50, com obras como On the road, de Jack Kerouac, que passou a ser reconhecido como símbolo de desordem e delinquência e Rebel without a case, de Robert Lindner, cuja adaptação para o cinema no filme Juventude transviada consagrou o ator James Dean com seu estilo "live fast, die young" como ícone jovem (GURSKI, 2012).

No final da década de 60, ocorreu a Revolução de Maio de 68; protagonizada pelos jovens franceses. Essa revolução marcou mundialmente a eclosão da maior rebelião juvenil e estudantil vista até então. Hobsbawn (2002), testemunha ocular do evento, afirma que o grande diferencial de tal revolução se deve ao fato de que seus grandes apelos não eram de ordem política, mas que representavam uma "revolução da vida cotidiana", ou seja, antes de uma revolta social era uma espécie de catarse de sentimentos reprimidos.

Ainda de acordo com o historiador, a década de 60 consolidou a juventude como grupo social com cara própria, tendo no jeans e no rock, dispositivos que favoreceram esse processo. Com isso houve uma exportação da cultura americana pela via do cinema e da televisão que popularizou o perfil juvenil, o qual passou a ser usado pela publicidade e maciçamente pelas novas estratégias de apelo ao consumo. (GURSKI, 2012, p. 52).

Garcia e Rocha (2008) destacam que na década de 60 a proliferação de símbolos adolescentes teve como correspondência a proliferação de identidades juvenis e ofereceu terreno para a mitificação da juventude que culminou na Revolução Juvenil de 68, realizando o mito da juventude como entidade autônoma que buscava uma cultura própria independente do mundo dos adultos. No entanto, esse processo não se sustentou, uma vez que ocorreram mudanças na sociedade e nos padrões socioculturais que culminaram com a emergência da lógica do consumo. 
Não podemos deixar de destacar, ainda nos anos 60 e 70, os movimentos da contracultura e dos bippies, que "ameaçavam" a ordem social com sua atitude crítica. Na passagem dos anos 70 para os anos 80, o capital se aproveitou diante de uma juventude que se revelara um poderoso exército de consumidores, livres de freios morais e religiosos que regulavam a relação do corpo com os prazeres e desligados de discursos tradicionais (KEHL, 2004).

A lógica do consumo passou, portanto, a fornecer uma multiplicidade de referências e opções que permitiram que aquilo que era próprio da cultura juvenil fosse apropriado pelo tecido social como traços idealizados de estilos de vida. Assim, podemos dizer que a mitificação da juventude deu lugar à idealização da juventude, à medida que suas diversas representações foram apropriadas pela lógica do consumo. Esse olhar idealizado, que a sociedade contemporânea dirige ao adolescente, foi facilitado pela cultura de consumo e pelo culto à liberdade (GARCIA; ROCHA, 2008).

Pode-se dizer que a adolescência passou a ocupar o lugar de ideal cultural não só pelo fato de levar os sujeitos a quererem permanecer nesta etapa da vida, mas também por ditar tendências mercadológicas, culturais e de lazer. Nesse sentido, imagens e insígnias adolescentes passaram a ser vendidas e cultuadas como aquilo que deveria ser desejado por todos; elevadas à categoria de modelo identificatório para pessoas de todas as faixas etárias, configurando um estilo que influencia modos de vida (GARCIA; ROCHA, 2008).

A imagem de cada geração traduz os conflitos vividos em cada momento histórico. Gurski (2012) aponta que a geração dos anos 60 e 70 ficou marcada como sendo idealista e utópica e em relação à qual a juventude dos anos 80 foi considerada individualista, consumista e indiferente aos assuntos públicos. Por fim, a geração dos anos 90 foi representada como rebelde e desregrada tal como a geração dos anos 60 , tendo suas ocupações do espaço público associadas à violência e ao vandalismo.

Os jovens voltaram a ocupar o primeiro lugar na mídia com o boom de revistas e jornais destinados ao mundo teen, sobretudo com matérias dirigidas aos adultos e aos impasses enfrentados para lidar com a condição juvenil, fazendo com que ocupassem o lugar de "tutores da desordem", só que dessa vez sem a tolerância do início dos tempos modernos. 
Entretanto, apesar dessa midiatização crescente da juventude nos meios de comunicação, os jovens continuam sendo "semi-invisíveis" na medida em que não podem ser vistos, ouvidos e compreendidos como sujeitos que têm questões próprias (ABRAMO, 1994). Nos anos 2000 continuamos a assistir a midiatização da juventude, mas ganha destaque o fenômeno do prolongamento da adolescência. Um exemplo disso é que, recentemente, uma nova orientação, para psicólogos americanos, passou a pregar que a adolescência deve ir até os 25 anos, e não apenas até os 18 anos como estava previsto anteriormente.

Estudos apontam que este prolongamento da adolescência é um fenômeno característico do nosso tempo, sendo que nos últimos anos assistimos a uma mudança nos limites de idade que definem a adolescência, que antes começava aos 12 e terminava aos 18 anos.

Jeammet (2005) se utiliza do neologismo adultescência para designar esse fenômeno e considera que na contemporaneidade está cada vez mais fácil fixar o início da adolescência a partir das manifestações da puberdade no corpo, mas por outro lado, fica difícil determinar o seu fim. Temos acompanhado uma puberdade cada vez mais precoce (na Idade Média, por exemplo, o aparecimento da menstruação se dava por volta dos 17 anos, ao passo que hoje se dá por volta dos 13 anos) e uma indeterminação do término da adolescência.

A antecipação da puberdade pode ser compreendida pelo maior apelo para o amadurecimento sexual determinado pelo imaginário veiculado pelos meios de comunicação. Além disso, com a liberalização dos costumes, os adolescentes passaram a ter acesso às atividades sexuais e ao conhecimento cada vez mais cedo, no entanto, houve um prolongamento da dependência dos pais, seja no plano afetivo, seja no plano material (CASTRO, 2009).

O prolongamento da escolaridade, o alargamento do tempo de formação profissional (que pode chegar até os 25 anos ou mais), bem como a demora ao ingresso na vida profissional e/ou para estabelecer laços conjugais são fatores que contribuem para esse aumento da dependência. Outro fator a ser considerado é a idealização da adolescência que tem levado à ocorrência de comportamentos pseudoadolescentes nos jovens pré-púberes (que imitam as atitudes dos mais velhos) e ao surgimento de uma "pós-adolescência" que prolonga a dependência infantil e posterga o ingresso à vida adulta (JEAMMET, 2005). 
Matheus (2010) aponta que a descontinuidade entre escola e mercado de trabalho se intensificou no final do século XX, contribuindo para a postergação do ingresso ao mundo adulto. Para o autor, a justificativa para tal descontinuidade se deve tanto pela inadequação entre os anseios juvenis, a preparação ofertada pela escola e as oportunidades encontradas após a formação quanto pelo desemprego crescente. Esse cenário acaba por se configurar como obstáculo para a saída dos jovens da casa dos pais, tornando a passagem para a vida adulta incerta e imprecisa.

\section{CONCLUSÃO}

A figura do adolescente é retratada de forma ambivalente pela cultura, afinal sua indeterminação é um terreno propício para projeções dos adultos e da mídia. Neste artigo tentamos demonstrar a leitura e compreensão da Psicanálise acerca da adolescência como sendo articulada às questões sócio-culturais que atravessam o sujeito no seu tempo. Deste modo, a psicanálise cumpriria seu papel de leitura da subjetividade e de seus impasses como nos propõe Birman (2006).

Buscamos assim demonstrar a importância de analisar os adolescentes a partir de sua relação com a cultura na qual estão inseridos, contribuindo para diminuir os preconceitos da concepção naturalista que transforma questões que tem origem social em algo inato, universal e desinteressado, criando práticas e modos de pensar estabelecidas como naturais e que ocultam o jogo de forças presente no cenário social.

\section{REFERÊNCIAS}

ABRAMO, H. W. Cenas juvenis: punks e darks no espetáculo urbano. São Paulo: Ed. Página Aberta, 1994.

ARIÉS, P. História Social da Família e da Criança. Rio de Janeiro: Guanabara, 2012. 
BERTOL, C. E.; SOUZA, M. Transgressões e Adolescência: Individualismo, Autonomia e Representações Identitárias. Psicologia: Ciência e Profissão, v. 30, n. 44, p. 824839, 2010.

BIRMAN, J. Tatuando o desamparo: a juventude na atualidade. In: CARDOSO, M. R. Adolescentes. São Paulo: Escuta, 2006.

CALLIGARIS, C. A Adolescência. São Paulo: Publifolha. 2000.

CARDOSO, M. R. Adolescentes. São Paulo: Escuta, 2006.

COIMBRA, C. C. BOCCO, F.; NASCIMENTO, M. L. Subvertendo o conceito de adolescência. Arquivos Brasileiros de Psicologia, v. 57, n. 1, p. 2-11, 2005.

EIZIRIK, L. C. O Ciclo da Vida Humana. Artmed: Porto Alegre, 2009.

FREUD, S. Três Ensaios sobre a Teoria da Sexualidade (1905). Rio de Janeiro: Imago, 1996.

FREUD, S. Psicologia de massas e análise do eu (1921). São Paulo: Companhia das Letras, 2010.

FOUCAULT, M. História da Sexualidade: a vontade de saber. Rio de Janeiro: Graal, 1988.

GARCIA, C. A.; ROCHA, A. P. R. A Adolescência como ideal cultural contemporâneo. Psicol. cienc. prof. [online], v. 28, n. 3, p. 622-631, 2008.

GOMES, V. R. R. Adolescentes na contemporaneidade: desamparo e laços fragilizados em meio aos "ideais" da sociedade de consumo (Dissertação de Mestrado) - Universidade Estadual de Maringá, Maringá, 2014. 
GURSKI, R. Três Ensaios sobre juventude e violência. São Paulo: Escuta, 2012.

HOBSBAWN, E. Tempos interessantes: uma vida no século XX. São Paulo: Companhia das Letras, 2002.

JEAMMET, P. Novas Problemáticas da Adolescência: evolução e manejo da dependência. São Paulo: Casa do Psicólogo, 2005.

KEHL, M. R. A frátria órfã: conversas sobre a juventude. São Paulo: Olho d'Água, 2004 .

LEVISKY, D. L. Adolescência: reflexões psicanalíticas. São Paulo: Casa do Psicólogo. 1998.

MATHEUS, T. C. Ideais na adolescência: falta (d)e perspectivas na virada do século. Annamblume: FAPESP, 2002.

MATHEUS, T. C. Adolescência: história e política do conceito na Psicanálise. São Paulo: Casa do Psicólogo, 2010.

TUBERT, S. A Morte e o Imaginário na Adolescência. Rio de Janeiro: Companhia de Freud, 1999.

Recebido em: 24 de abril de 2017 Aceito em: 04 de outubro de 2017 